\title{
Discriminating between lanthanide ions: self-assembly of heterodimetallic triple-stranded helicates
}

\author{
Nicolas André, ${ }^{a}$ Rosario Scopelliti, ${ }^{a}$ Gérard Hopfgartner, ${ }^{b}$ Claude Piguet ${ }^{c}$ and Jean-Claude G. \\ Bünzli*a \\ a Institute of Molecular and Biological Chemistry, BCH, Swiss Federal Institute of Technology, \\ CH-1015-Lausanne,Switzerland.E-mail: jean-claude.bunzli@epfl.ch \\ ${ }^{b}$ F. Hoffmann-La Roche Ltd, Pharmaceuticals Division, PRNS 68/142, CH-4070 Basel, Switzerland \\ ${ }^{c}$ Department of Inorganic, Analytical and Applied Chemistry, University of Geneva, 30 quai E. Ansermet, \\ CH-1211 Geneva 4, Switzerland
}

Received (in Cambridge, UK) 5th October 2001, Accepted 7th December 2001

First published as an Advance Article on the web 17th January 2002

A bis-terdentate segmental ligand has been designed which self-assembles with lanthanide ions of different size to yield heterodimetallic triple-stranded helicates

Luminescent lanthanide complexes are increasingly used as diagnostic tools in biomedical analysis, as responsive analytical systems, ${ }^{1}$ as luminescent labels for enhanced imaging of cancer $^{2}$ or for fluoroimmunoassays, ${ }^{3}$ and in colour-tailored fluorophores for simultaneous detection of multiple targets on DNA strands. ${ }^{4}$ In this context, heterodimetallic molecules are potentially interesting because they would combine two luminescent or one magnetic and one luminescent centres in one probe. The recognition of one specific lanthanide ion in the presence of others is, however, a very difficult challenge, in view of the limited difference in the size of these ions and of their similar chemical properties. ${ }^{5}$ We have previously shown that planar tridentate ligands based on the bis(benzimidazole)pyridine framework display a size-discriminating effect, resulting in an unusual selectivity for the mid-range $\mathrm{Ln}^{\mathrm{III}}$ ions. ${ }^{6} \mathrm{On}$ the other hand, the stability of complexes with the diethylamide derivative of 2,6-pyridine dicarboxylic acid smoothly increases along the $\mathrm{Ln}^{\mathrm{III}}$ series. ${ }^{7}$ In parallel, we have designed symmetric ditopic ligands (Scheme 1) which self-assemble with $\mathrm{Ln}^{\mathrm{III}}$ ions to yield thermodynamically stable triple-stranded homodimetallic helicates in organic solvents $\left(\mathrm{L}^{\mathrm{A}}, \mathrm{L}^{\mathrm{B}}\right)^{8,9}$ or in water $\left(\mathrm{L}^{\mathrm{C}}\right) .^{10}$ Combining the two approaches, we present here the synthesis of the unsymmetrical ditopic ligand $\mathrm{L}^{\mathrm{AB}}$, bearing one benzimidazole-pyridine-carboxamide unit programmed to complex preferentially the smaller lanthanide ions and one, less strongly coordinating, bis(benzimidazole)pyridine moiety which interacts preferentially with the larger $\mathrm{Ln}^{\mathrm{III}}$ ions. We demonstrate that this molecular engineering indeed leads to the simultaneous recognition of two different lanthanide ions provided their size difference is large enough.

Ligand $\mathrm{L}^{\mathrm{AB}}$ has been synthesized using the strategies developed earlier ${ }^{8,9}$ and has been fully characterised. $\dagger$ Its

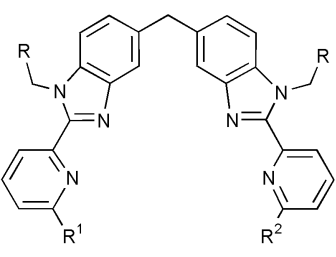

$$
\begin{aligned}
& \mathrm{R}=\mathrm{H} \\
& \mathrm{R}^{1}=\mathrm{R}^{2}=
\end{aligned}
$$<smiles>[2H]CN(CC)C(=O)c1cccc(-c2nc3cc(Cc4ccc5c(c4)N=C4c6cccc(n6)C5=Nc5ccccc5N(CC)N4CC)ccc3n2CC)n1</smiles>

Scheme 1 interaction with $\mathrm{Ln}^{\mathrm{III}}$ ions in acetonitrile was initially monitored by ${ }^{1} \mathrm{H}$ NMR spectroscopy, titrating $\mathrm{L}^{\mathrm{AB}}$ by $\mathrm{La}^{\mathrm{III}}$ in the range $R$ $=[\mathrm{La}]_{\mathrm{t}} /\left[\mathrm{L}^{\mathrm{AB}}\right]_{\mathrm{t}}=0.3-1.0$. When the metal ion is added to the ligand, the signals of the latter broaden and diminish, while bands attributable to two different species appear. Analysis of these spectra and comparison with the data previously reported for the complexes with $\mathrm{L}^{\mathrm{A}}$ and $\mathrm{L}^{\mathrm{B} 8,9}$ lead us to conclude that these species correspond to the expected isomers (HHH)$\left[\mathrm{La}_{2}\left(\mathrm{LAB}_{3}\right]^{6+}\right.$ and $(\mathrm{HHT})-\left[\mathrm{La}_{2}\left(\mathrm{~L}^{\mathrm{AB}}\right)_{3}\right]^{6+}$. All the signals for the $(\mathrm{HHH})^{11}$ species are observed: five triplets for methyl groups 5, 14, 19, 25 and 27; ten doublets of quartets for the diastereotopic methylene protons 4, 13, 18, 24 and 26; two doublets for protons 9 and two singlets for protons 8 and 10. For the (HHT) species, some of the signals overlap so that all the resonances cannot be identified, but the predicted six singlets are observed for protons 8 and 10. At the stoichiometric ratio $R$ $=2 / 3$ the proportion of the $(\mathrm{HHH})$ and $(\mathrm{HHT})$ species amounts to 85 and $15 \%$, respectively, which significantly deviates from the statistics $(25,75 \%)$ and suggests a preference for the coordination of each lanthanide to three identical terdentate segments of the ligands. A similar titration of $\mathrm{L}^{\mathrm{AB}}$ with $\mathrm{Lu}^{\mathrm{III}}$ reveals (i) a less important proportion of the (HHH) 2:3 complex $(65 \%$ for $R=2 / 3)$ and (ii) the presence of other species with $\mathrm{Lu}: \mathrm{L}^{\mathrm{AB}}$ stoichiometry $2: 2,1: 2$ and, possibly, $1: 3$, pointing to $(\mathrm{HHH})-\left[\mathrm{Lu}_{2}\left(\mathrm{~L}^{\mathrm{AB}}\right)_{3}\right]^{6+}$ being less stable than its $\mathrm{La}^{\mathrm{III}}$ counterpart. The spectrum of a solution containing a $\mathrm{La}$ : $\mathrm{Lu}: \mathrm{L}^{\mathrm{AB}}$ ratio equal to $1: 1: 3$ is comprised of a relatively small number of signals (Fig. 1) revealing the presence of a single major species ( $\mathrm{ca}$. 90\%) corresponding to (HHH)-[LaLu$\left.\left(\mathrm{L}^{\mathrm{AB}}\right)_{3}\right]^{6+}$. Weak interstrand NOE effects between $\mathrm{H}^{4} / \mathrm{H}^{11}, \mathrm{H}^{7} /$ $\mathrm{H}^{13}$, and $\mathrm{H}^{13} / \mathrm{H}^{18}$ confirm the helical wrapping of the ligands ${ }^{12}$ and detailed analyses of the multiplicities and chemical shifts unambiguously points to $\mathrm{Lu}^{\mathrm{III}}$ being coordinated to the amide groups of the three ligand strands, as planned in the ligand design.

The speciation in solutions $10^{-3} \mathrm{~mol} \mathrm{dm}^{-3}$ in acetonitrile featuring a stoichiometric ratio $\mathrm{Ln}: \mathrm{Ln}^{\prime}: \mathrm{L}^{\mathrm{AB}}$ equal to $1: 1: 3$ was further investigated by ES-MS spectroscopy. The spectra mainly display signals arising from the homo- and heterodimetallic species, which are easily identified by their perchlorate adducts: $\left\{\left[\mathrm{Ln}_{2}\left(\mathrm{LAB}_{3}\right]\left(\mathrm{ClO}_{4}\right)_{n}\right\}^{(6-n)+}, \quad\left\{\left[\mathrm{Ln}^{\prime} 2^{-}\right.\right.\right.$ $\left.\left.\left(\mathrm{L}^{\mathrm{AB}}\right)_{3}\right]\left(\mathrm{ClO}_{4}\right)_{n}\right\}^{(6-n)+}$ and $\left\{\left[\mathrm{LnLn}^{\prime}\left(\mathrm{L}^{\mathrm{AB}}\right)_{3}\right]\left(\mathrm{ClO}_{4}\right)_{n}\right\}^{(6-n)+}(n=$

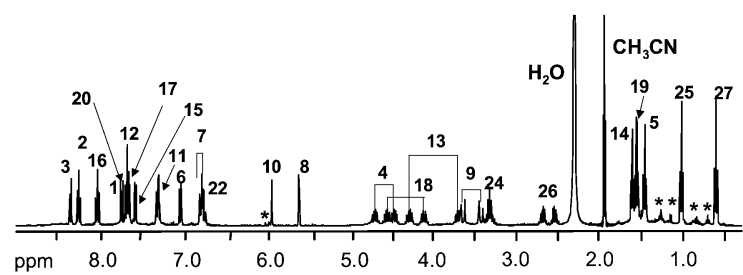

Fig. $1^{1} \mathrm{H}$ NMR spectrum of a mixture of $\mathrm{La}^{\mathrm{III}}\left(10^{-2} \mathrm{~mol} \mathrm{dm}{ }^{-3}\right), \mathrm{Lu}^{\mathrm{III}}\left(10^{-2}\right.$ mol dm$\left.{ }^{-3}\right)$ and $\mathrm{L}^{\mathrm{AB}}\left(3 \times 10^{-2} \mathrm{~mol} \mathrm{dm}^{-3}\right)$ in $\mathrm{CD}_{3} \mathrm{CN}$ at $295 \mathrm{~K}$. Stars denote identified signals from homodimetallic species. 
Table 1 Percentage of heterodimetallic species in acetonitrile as determined by ES-MS (left) in $10^{-3} \mathrm{~mol} \mathrm{dm}{ }^{-3}$ solutions and ${ }^{1} \mathrm{H}$ NMR (right) in $10^{-2}$ mol dm-3 solutions

\begin{tabular}{llll}
\hline $\mathrm{Ln}$ & $\mathrm{Ln}^{\prime}$ & ES-MS & ${ }^{1} \mathrm{H} \mathrm{NMR}$ \\
\hline $\mathrm{La}$ & $\mathrm{Lu}$ & 89 & 90 \\
$\mathrm{La}$ & $\mathrm{Yb}$ & $-^{a}$ & 87 \\
$\mathrm{La}$ & $\mathrm{Er}$ & 65 & 81 \\
$\mathrm{La}$ & $\mathrm{Eu}$ & 70 & $-_{a}^{a}$ \\
$\mathrm{Pr}$ & $\mathrm{Er}$ & 57 & 65 \\
$\mathrm{Eu}$ & $\mathrm{Lu}$ & 55 & $\mathrm{-a}^{a}$ \\
$\mathrm{Eu}$ & $\mathrm{Er}$ & 51 & \\
$\mathrm{Eu}$ & $\mathrm{Tb}$ & & \\
${ }^{a}$ Not determined. & & & \\
\hline
\end{tabular}

0-3). The percentages of the heterodimetallic species are reported in Table 1 for several LnLn' couples, along with those determined by ${ }^{1} \mathrm{H}$ NMR spectroscopy on $10^{-2}$ mol $\mathrm{dm}^{-3}$ solutions in $\mathrm{CD}_{3} \mathrm{CN}$. The two sets of data are in good agreement, pointing to stable helicates, since the speciation does not change in the range $10^{-2}-10^{-3} \mathrm{M}$. For several systems, the proportion of heterodimetallic species deviates substantially from the statistical distribution $(50 \% ; \Delta G(298)=-3.4 \mathrm{~kJ}$ $\mathrm{mol}^{-1}$ for the equilibrium $\left.\mathrm{Ln}_{2}+\mathrm{Ln}_{2}{ }_{2} \rightleftharpoons 2 \mathrm{LnLn}^{\prime}\right)$ pointing to an enrichment in the heterodimetallic complexes, which is largest for LaLu $\left(\approx 90 \% ; \Delta(\Delta G)=-7.4 \mathrm{~kJ} \mathrm{~mol}^{-1}\right)$. In fact, this enrichment is a relatively smooth function of the difference between the ionic radii of the two lanthanide ions as shown on Fig. 2, ${ }^{13}$ in line with the stability data reported for the monometallic compounds. ${ }^{6,7}$ A substantial proportion of heterodimetallic helicate $\left(>70 \% ; \Delta(\Delta G)<-0.8 \mathrm{~kJ} \mathrm{~mol}^{-1}\right)$ is obtained when $\Delta r_{\mathrm{i}}$ is larger than $0.1 \AA$.

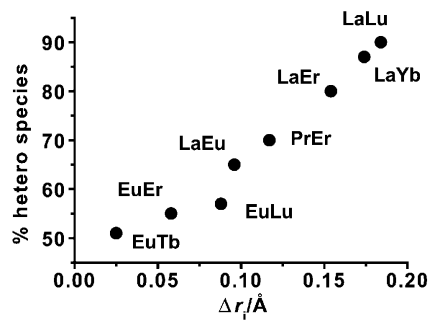

Fig. 2 Percentage of heterodimetallic species as a function of the ionic radius difference for nine-coordinate $\mathrm{Ln}^{3+} .14$

Finally, we were able to obtain single crystals suitable for Xray diffraction for the $\mathrm{LaEu}$ heterodimetallic helicate. $\S$ Its molecular structure presented in Fig. 3 fully confirms the structural data obtained in solution, the three ligand strands being helically wrapped around the two metal ions and the three amide functions being coordinated to the heaviest metal ion, $\mathrm{Eu}^{\mathrm{III}}$. Bond lengths and angles of the coordination polyhedron are standard for the two ions and compare well, after correction for ionic radius differences, with those found in the previously reported homodimetallic structures of $\left[\mathrm{Eu}_{2}\left(\mathrm{~L}^{\mathrm{A}}\right)_{3}\right]^{6+}, 8$ $\left[\mathrm{Tb}_{2}\left(\mathrm{~L}^{\mathrm{B}}\right)_{3}\right]^{6+}, 9$ and $\left[\mathrm{Ln}_{2}\left(\mathrm{LC}^{\mathrm{C}}-2 \mathrm{H}\right)_{3}\right](\mathrm{Ln}=\mathrm{Eu}, \mathrm{Tb}, \mathrm{Yb}){ }^{10}$

In conclusion, we have presented here the first design of an unsymmetrical ditopic ligand coded for the supramolecular recognition of two different lanthanide ions. A recent paper reported on the first structurally characterized example of a heterodimetallic $\mathrm{LaYb}$ complex obtained with a potentially decadentate Schiff base. ${ }^{14}$ However, the corresponding crystals were isolated from a mixture of homo- and hetero-dimetallic complexes, that is, this ligand displays unspecific binding to any lanthanide ion. Since synthetic strategies for the substitution of the ditopic symmetrical receptors at the pyridine 4-position are at hand, ${ }^{15,16}$ we are working toward achieving a better finetuning of the selectivity of unsymmetrical receptors, allowing the recognition of pairs of lanthanide ions with a difference in their ionic radius smaller than $0.1 \AA$.

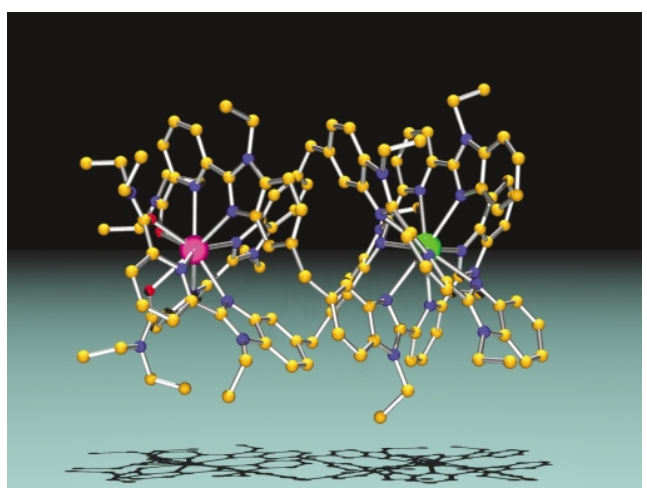

Fig. 3 Molecular structure of $\left[\mathrm{LaEu}\left(\mathrm{L}^{\mathrm{AB}}\right)_{3}\right]\left(\mathrm{ClO}_{4}\right)_{6} \cdot 3 \mathrm{MeCN} \cdot 3 \mathrm{EtCN}$.

This research is supported through grants from the Swiss National Science Foundation. We thank Dr M. Elhabiri for his help in the synthesis of ligand $\mathrm{L}^{\mathrm{AB}}$.

\section{Notes and references}

$\dagger$ Calc. for $\mathrm{C}_{43} \mathrm{H}_{43} \mathrm{~N}_{9} \mathrm{O} \cdot 0.5 \mathrm{H}_{2} \mathrm{O}: \mathrm{C}, 72.65 ; \mathrm{H}, 6.24 ; \mathrm{N}, 17.73$. Found: $\mathrm{C}$ $72.51 ; \mathrm{H}, 6.28 ; \mathrm{N}, 17.60 \%$.

\$HH stands for head-head-head and means that the three ligand strands bind each La(III) ion through the same functional end; HHT stands for headhead-tail and indicates that two ligand strands bind one La(III) ion through the same functional end whereas the third ligand binds through the other functional end. These two isomers have different symmetry and they may be readily recognised in the NMR spectra.

$\S$ Crystal data: $\mathrm{C}_{144} \mathrm{H}_{153} \mathrm{~N}_{33} \mathrm{O}_{27} \mathrm{Cl}_{6}$ EuLa, $M=3281.56$, monoclinic, space group $P 2_{1} / c, a=14.759(3), b=26.369(5), c=37.217(7) \AA, \beta=$ $90.12(3)^{\circ}, V=14484(5) \AA^{3}, Z=4, \mu=0.915 \mathrm{~mm}^{-1}, T=143(2) \mathrm{K}$, $F(000)=6744,46327$ reflections collected, 17176 independent reflections, 1805 parameters, $R 1[I>2 \sigma(I)]=0.0669, w R 2$ (all data) $=0.1981$. Mean distances: Eu-N 2.603(7), Eu-O 2.395(6), La-N, 2.648(7) ̊.. Due to the large number of parameters, the structure has been refined using the fullmatrix-block on $F^{2}$ method with fixed anisotropic displacement parameters. Solvent molecules occupy what would have been voids in the crystal lattice and are not well defined.

CCDC reference number 172173. See http://www.rsc.org/suppdata/cc/ b1/b109065h/ for crystallographic data in CIF or other electronic format.

1 D. Parker, Coord. Chem. Rev., 2000, 205, 109.

2 D. J. Bornhop, D. S. Hubbard, M. P. Houlne, C. Adair, G. E. Kiefer, B. C. Pence and D. L. Morgan, Anal. Chem., 1999, 71, 2607.

3 V. W. W. Yam and K. K. W. Lo, Coord. Chem. Rev., 1999, 184 157.

4 J. Y. Chen and P. R. Selvin, J. Am. Chem. Soc., 2000, 122, 657.

5 C. Piguet and J.-C. G. Bünzli, Chem. Soc. Rev., 1999, 28, 347.

6 S. Petoud, J.-C. G. Bünzli, F. Renaud, C. Piguet, K. J. Schenk and G. Hopfgartner, Inorg. Chem., 1997, 36, 5750.

7 F. Renaud, C. Piguet, G. Bernardinelli, J.-C. G. Bünzli and G. Hopfgartner, Chem. Eur. J., 1997, 3, 1646.

8 C. Piguet, J.-C. G. Bünzli, G. Bernardinelli, G. Hopfgartner and A. F. Williams, J. Am. Chem. Soc., 1993, 115, 8197.

9 N. Martin, J.-C. G. Bünzli, V. McKee, C. Piguet and G. Hopfgartner, Inorg. Chem., 1998, 37, 577.

10 M. Elhabiri, R. Scopelliti, J.-C. G. Bünzli and C. Piguet, J. Am. Chem. Soc., 1999, 121, 10747.

11 C. Piguet, G. Bernardinelli and G. Hopfgartner, Chem. Rev., 1997, 97, 2005

12 C. Piguet, J.-C. G. Bünzli, G. Bernardinelli, G. Hopfgartner, S. Petoud and O. Schaad, J. Am. Chem. Soc., 1996, 118, 6681.

13 J.-C. G. Bünzli, in Rare Earths, ed. R. Saez Puche and P. Caro, Editorial Complutense, Madrid, 1998, pp. 223-259.

14 J. P. Costes, F. Dahan, A. Dupuis, S. Lagrave and J. P. Laurent, Inorg Chem., 1998, 37, 153.

15 A.-S. Chauvin, R. Tripier and J.-C. G. Bünzli, Tetrahedron Lett., 2001 42, 3089.

16 C. Platas, M. Elhabiri, M. Hollenstein, J.-C. G. Bünzli and C. Piguet, J. Chem. Soc., Dalton Trans., 2000, 2031 